\title{
Effect of Cisplatin on the Kidney of the Albino Rat and Possible Protective Role of Vitamin C
}

\author{
REEM H. MOHAMED, M.Sc.; YEHIA M. YOUSSEF, M.D.; MANAL H. EL-KAFRAWY, M.D.; \\ OLA A. EL-SAYED, M.D. and AMINA M. TOLBA, M.D.
}

The Department of Anatomy, Faculty of Medicine, Al-Azhar University, Cairo

\begin{abstract}
Background: Cisplatin has a major nephrotoxic effect.

Aim of Study: To evaluate the protective effect of vitamin $\mathrm{C}$ against cisplatin-induced nephrotoxicity.

Material and Methods: Sixty adult albino rats divided into 5 groups; group I (10 rats; control), group II (10 rats); received single dose of cisplatin $6 \mathrm{mg} / \mathrm{kg}$ IP. Group III (10 rats); received single dose of cisplatin $6 \mathrm{mg} / \mathrm{kg}$ IP 6 hours after single dose of oral vitamin C $350 \mathrm{mg} / \mathrm{kg}$. Group IV (15 rats); received single dose of cisplatin $2 \mathrm{mg} / \mathrm{kg} /$ week for 4 weeks IP and subdivided into three subgroups ( 5 rats each). Group $\mathrm{V}$ (15 rats); received single dose of cisplatin $2 \mathrm{mg} / \mathrm{kg} /$ week for 4 weeks IP 6 hours after single dose of oral vitamin C $350 \mathrm{mg} / \mathrm{kg}$ and subdivided into three subgroups ( 5 rats each). Kidneys were dissected and stained by (H\&E), Masson's trichrome (MT) and Periodic acid Schiff (PAS) and examined by light microscopy, and fresh tissue taken from group I, IV$\mathrm{B}$ and $\mathrm{V}-\mathrm{C}$ examined by electron microscopy.
\end{abstract}

Results: Our results showed toxic effect of cisplatin on renal glomeruli and proximal tubular lining in group II with improvement in group III, chronic toxicity effect in group IV$\mathrm{C}$ in the form of hyaline casts and thickened BM with apparent improvement in group $\mathrm{V}$.

Conclusion: We conclude that the vitamin $\mathrm{C}$ has a protective effect against cisplatin- induced nephrotoxicity.

Key Words: Kidney - Cisplatin - Vitamin C - EM.

\section{Introduction}

CISPLATIN is a major chemotherapeutic drug used for treatment of various types of malignant tumors including lung small cell carcinoma, ovarian carcinoma, lymphomas and germ cell tumors, $20 \%$ of patients receiving high-dose cisplatin or long term therapy have severe renal dysfunction [1] Cisplatin has a number of side-effects as: Nephrotoxicity, neurotoxicity, nausea, vomiting, ototoxic-

Correspondence to: Dr. Amina M. Tolba, The Department of Anatomy, Faculty of Medicine, Al-Azhar University, Cairo ity, electrolyte disturbance, bone marrow suppression and hemolytic anemia [2]. In rats, the proximal tubules of S3 segment accumulates the highest concentration of cisplatin, followed by the distal collecting tubules and proximal tubules of S 1 segment [3]. In vivo mechanisms of cisplatin nephrotoxicity are complex and involve oxidative stress, apoptosis, inflammation, and fibrogenesis. High concentrations of cisplatin induce necrosis in proximal tubular cells, whereas lower concentrations induce apoptosis [4]. Reactive oxygen species (ROS) directly act on cell components, including lipids, proteins and DNA, and destroy their structure and implicated in the pathogenesis of acute cisplatin-induced renal injury [5].

There is increasing evidence that administration of antioxidants may reduce the nephrotoxicity of cisplatin without interfering with its anti-tumor activity [6]. Ascorbic acid is well known for its antioxidant activity acting as a reducing agent to reverse oxidation in liquids. When there are more free radicals (reactive oxygen species) in the human body than antioxidants, the condition is called oxidative stress [7]. Some compounds with antioxidant property such as silymarin, vitamin $\mathrm{C}$ and vitamin $\mathrm{E}$ have been found to have renoprotective function in animal studies [8] . Vitamin C or Lascorbic acid or L-ascorbate is an essential nutrient for humans and certain other animal species. In living organisms ascorbate acts as an antioxidant by protecting the body against oxidative stress [9] Vitamin C shows protection in a dose-dependent manner on cisplatin-induced oxidative damage on rat kidneys [10].

\section{Patients and Methods}

This study included 60 adult albino rats, weighing 200-250g. housed in cages, one animal each, 
under good hygienic conditions, fed ad libitium and allowed free water supply.

Cisplatin obtained from Bristol-Myers Squibb Company was available as ampoules $10 \mathrm{mg} / 10 \mathrm{ml}$ saline, $(1 \mathrm{mg} / \mathrm{ml})$.

Vitamin C obtained from El-Hadidi Pharma Company was available as oral drops $1500 \mathrm{mg} /$ $15 \mathrm{ml},(100 \mathrm{mg} / \mathrm{ml})$.

The rats (at animal house Facuity of medicine El Azhar university) were divided into five groups:

- Group I(Control group): Included 10 rats, the animals of this group did not receive any medication.

- Group II: Included 10 rats received single dose of cisplatin $6 \mathrm{mg} / \mathrm{kg}$ intraperitoneally (IP) [11] and sacrificed after 4 weeks.

- Group III: Included 10 rats received single dose of cisplatin $6 \mathrm{mg} / \mathrm{kg}$ IP 6 hours after a single dose of oral vitamin C $350 \mathrm{mg} / \mathrm{kg}$ [11] and sacrificed after 4 weeks.

- Group IV: Included 15 rats, received single dose of cisplatin $2 \mathrm{mg} / \mathrm{kg} /$ week for 4 weeks IP [12] and subdivided into three subgroups (5 rats each); group IV-A were sacrificed after 2 weeks and group IV-B after 4 weeks from the beginning of the experiment, and group IV-C were sacrificed after 4 weeks from cisplatin withdrawal.

- Group V: Included 15 rats, received single dose of cisplatin $2 \mathrm{mg} / \mathrm{kg} /$ week for 4 weeks IP. Each dose was given 6 hours after a single dose of oral vitamin C $350 \mathrm{mg} / \mathrm{kg}$. This group was subdivided into three subgroups (5 rats each); group $\mathrm{V}$-A were sacrificed after 2 weeks and group VB after 4 weeks from the beginning of the experiment, and group V-C sacrificed after 4 weeks from cisplatin withdrawal.

All rats were anaesthetized using ether inhalation; both kidneys were extracted, fixed in $10 \%$ formalin solution and processed for preparation of paraffin blocks, and stained by Haematoxyline \& Eosin (H\&E), Masson's trichrome (MT) and Periodic acid Schiff (PAS) to be examined by light microscope. Some tissue from groups I, IV-B and $\mathrm{V}$-B were fixed in gluteraldehyde for preparation of ultra thin sections and stained with uranyl acetate and lead citrate to be examined by transmission electron microscope (TEM). Spescimens were eliminated and prosscesed at Institute for Fungi Faculty of Science and Histology Department AlAzhar University in 2015.

\section{Results}

This study included 60 rats divided into 5 groups; I, II, III (10 rats each), IV and V (15 rats each) divided into 3 subgroups; A, B and C (5 rats each).

Group I: (Control group; 10 rats):Showed average glomerular cellularity, patent Bowman's spaces, average proximal tubular lining with brush borders, average distal tubular lining and average interstitium (Fig. 1).

PAS: Showed more or less normal glomerular $\mathrm{BM}$ with preserved proximal tubular brush border (Fig. 7).

Masson's trichrome: Showed minimal distribution of collagen fibers in the renal interstitium (Fig. 13).

EM: Showed glomerular loops of capillaries lined by fenestrated endothelium resting on trilaminar glomerular basement membrane (BM), podocytes sending primary as well as secondary foot processes resting on the glomerular BM, narrow peri-glomerular spaces devoid of any cellular debris. The proximal tubular lining cells showed rounded mid-positioned nuclei with peripheral chromatin condensation and profuse tall microvilli forming the brush border. The distal convoluted tubules lacked the prominent microvilli and had less cytoplasm than those of the proximal convoluted tubules (Fig. 19).

Group II: (10 rats; received single dose of cisplatin $6 \mathrm{mg} / \mathrm{kg} I P$ ): Showed irregular shrunken congested glomeruli with dilated peri-glomerular spaces. Most of renal tubules showed well defined $\mathrm{BM}$, numerous cytoplasmic vacuoles of epithelial lining, and interstitial peri-vascular inflammatory cellular infiltrates (Fig. 2).

PAS: showed thickening of the basement membrane (BM) of the glomeruli, Bowman's capsule and tubules with distorted apical brush border (Fig. 8).

Masson's trichrome: Showed excess deposition of collagen fibers in the peri-tubular tissue of the renal cortex (Fig. 14).

Group III: (10 rats; received single dose of cisplatin $6 \mathrm{mg} / \mathrm{kg}$ IP six hours after a single dose of oral vitamin C $350 \mathrm{mg} / \mathrm{kg}$ ): Showed hypertrophy of glomeruli, widened peri-glomerular spaces and granularity of the cytoplasm of the renal tubular lining with decreased vacuoles (Fig. 3). 
PAS: Showed more or less normal basement membrane (BM) of the glomeruli, Bowman's capsule and tubules (Fig. 9).

Masson's trichrome: Showed minimal deposition of collagen fibers in the interstitium of the renal cortex (Fig. 15).

Group IV: (15 rats; received single dose of cisplatin $2 \mathrm{mg} / \mathrm{kg} /$ week for 4 weeks IP).

Group IV-A: (5 rats; sacrificed after 2 weeks from the beginning of the experiment): Showed congested glomerular and inter-tubular blood capillaries, edema and focal interstitial mononuclear cellular infiltrates (Fig. 4).

PAS: Showed thickening of the basement membrane (BM) of the glomeruli, Bowman's capsule and tubules.

Masson's trichrome: Showed minimal deposition of collagen fibers in the interstitium.

Group IV-B: (5 rats; sacrificed after 4 weeks from the beginning of the experiment): Showed shrunken and congested glomerular tuft with dilated peri-glomerular spaces. Renal tubules are cystically dilated with hyaline casts and numerous cytoplasmic vacuoles of epithelial lining. The interstitium showed peri-tubular inflammatory infiltrate.

PAS: Showed thickening of the basement membrane (BM) of the glomeruli, Bowman's capsule and tubules (Fig. 9).

Masson's trichrome: Showed deposition of excess collagen fibers in between the tubules in the renal cortex (Fig. 16).

$E M$ : showed areas of thickening of the glomerular basement membrane and effacement of the secondary foot processes of the podocytes. The proximal tubular lining cells showed dark nuclei with clumped chromatin, invagination of the nuclear envelope, vacuolization of the cytoplasm and ballooning of the mitochondria with loss of their cristae. The mitochondria were fewer than the normal group and the basal infoldings encircling the mitochondria were lost. The basement membrane was thickened with many large lysosomes, the distal tubular lining cells showed small dark electron dense nuclei and disorganization of the basal mitochondria with loss of their cristae (Fig. 20).

Group IV-C: (5 rats; sacrificed 4 weeks after withdrawal of cisplatin): Showed shrunken glomerular tuft, and widened peri-glomerular spaces.
Renal tubules are cystically dilated with hyaline casts and numerous cytoplasmic vacuoles of epithelial lining and thickened BM, congested renal blood vessels with focal interstitial and peri-tubular inflammatory infiltrate in all examined sections (Fig. 5).

PAS: Showed thickening of the basement membrane (BM) of the glomeruli, Bowman's capsule and tubules (Fig. 10).

Masson's trichrome: Showed interstitial dense deposition of collagen fibers (Fig. 17).

Group V: (15 rats; received single dose of cisplatin $2 \mathrm{mg} / \mathrm{kg} /$ week for 4 weeks IP):

Group V-A: (5 rats; sacrificed after 2 weeks from the beginning of the experiment): Showed marked improvement with more or less normally appearing glomeruli with normal cellularity and normal peri-glomerular spaces. Both proximal and distal tubules showed normal cellularity and uniform nuclei (Fig. 6).

PAS: Showed slight thickening of the glomerular basement membrane.

Masson's trichrome: Showed minimal deposition of collagen fibers in the interstitium.

Group V-B: (5 rats; sacrificed after 2 weeks from the beginning of the experiment): Showed marked improvement with slightly congested glomerular and inter-tubular blood capillaries, renal tubules with more or less normal epithelial lining with regression of vacuolar alteration.

PAS: Showed slight thickening of the glomerular basement membrane (Fig. 12).

Masson's trichrome: showed minimal deposition of collagen fibers in the renal interstitium (Fig. 18).

EM: Showed glomerular capillaries with fenestrated endothelium and podocytes resting on the tri-laminar basement membrane. The glomerular basement membrane was slightly thickened, the proximal tubular lining cells showed normal nuclei and mitochondria with intact cristae perpendicular to the thin basement membrane with intact apical microvilli and apical pinocytic vesicles, the distal tubular lining cells showed normal rounded and intact nuclei, few small microvilli and basal mitochondria with intact cristae (Figs. 21,22). 
Group V-C: (5 rats; sacrificed 4 weeks after withdrawal of cisplatin): Showed slight dilatation of peri-glomerular spaces, average renal tubules with lining epithelium showing slight vacuolar alteration and uniform nuclei.
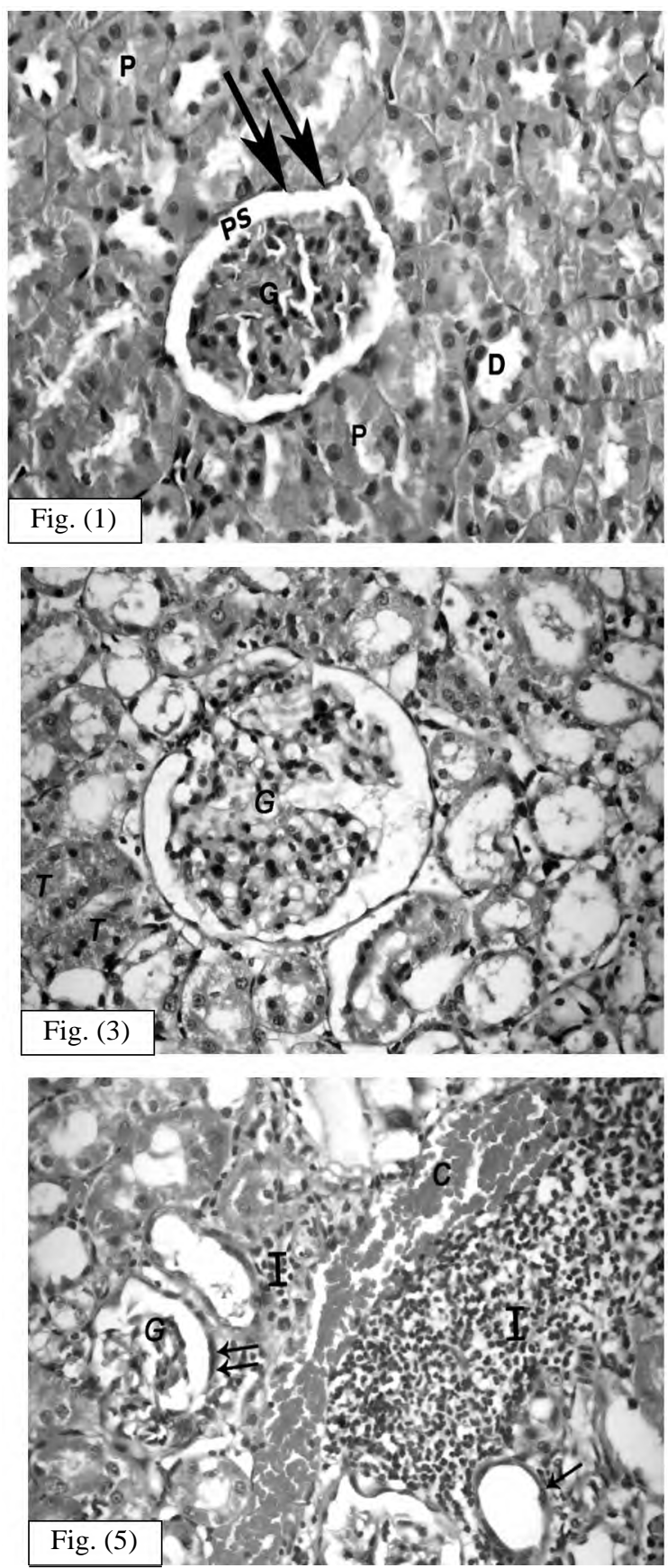

PAS: Showed slight thickening of the glomerular basement membrane.

Masson's trichrome: Showed minimal deposition of collagen fibers in the renal interstitium.
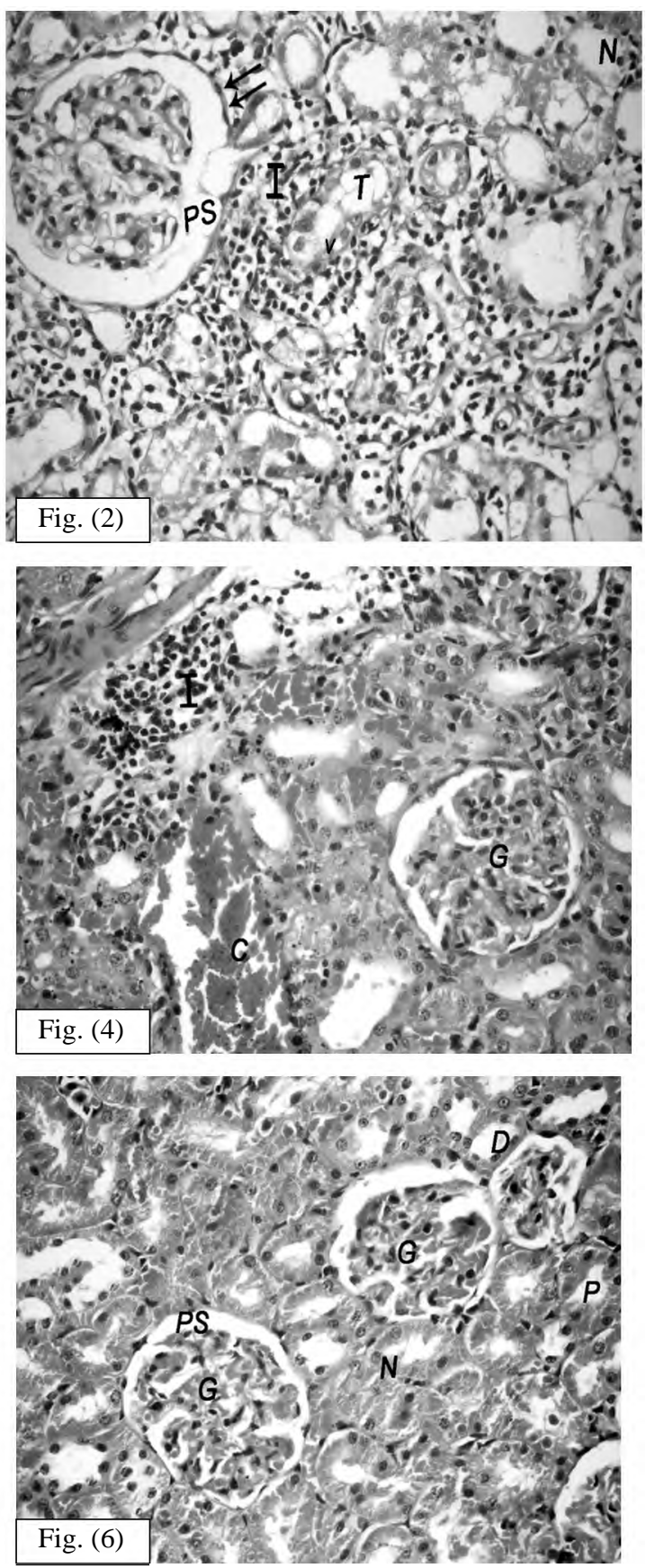

Fig. (1): Group I (control). Fig. (2): Group II: Showing shrunken irregular glomerulus (G), dilated peri-glomerular space (PS), numerous cytoplasmic vacuoles in most of renal tubules (T) with diffuse interstitial mononuclear cellular infiltrates (I). Fig. (3): Group III: Showed dilated peri-glomerular spaces with less cytoplasmic vacuoles in tubular epithelial lining cells renal tubules (T). Fig. (4): Group IV- A: Showed congested glomerular (G) and renal blood vessels (C) with focal mononuclear cellular infiltration (I). Fig. (5): Group IV-C: Showing shrunken glomerular tuft (G), thickening of the tubular basement membrane (arrow), congestion (c) of renal blood vessels and focal inflammatory cellular infiltration (I). Fig. (6): Group V-A: Showing average glomerular cellularity (G) with average peri-glomerular space (PS). Both proximal (P) and distal tubules (D) show normal cellularity and uniform nuclei. (H\&E X400). 


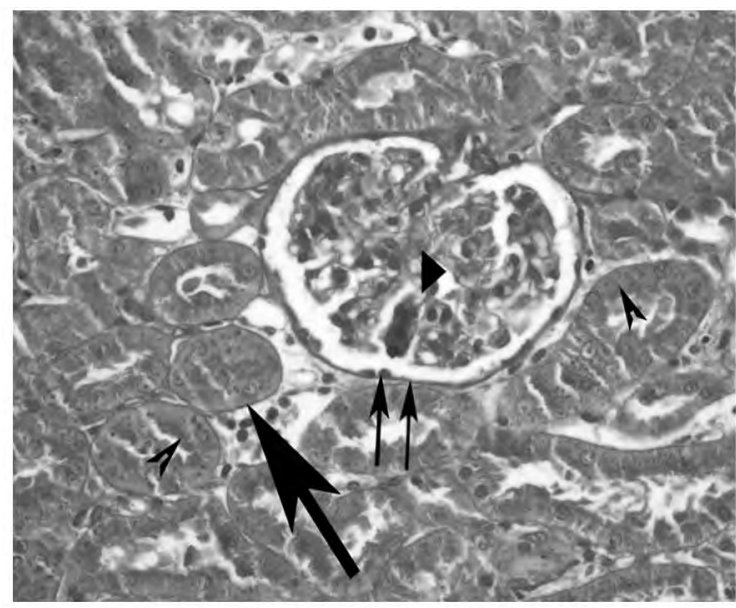

Fig. (7)

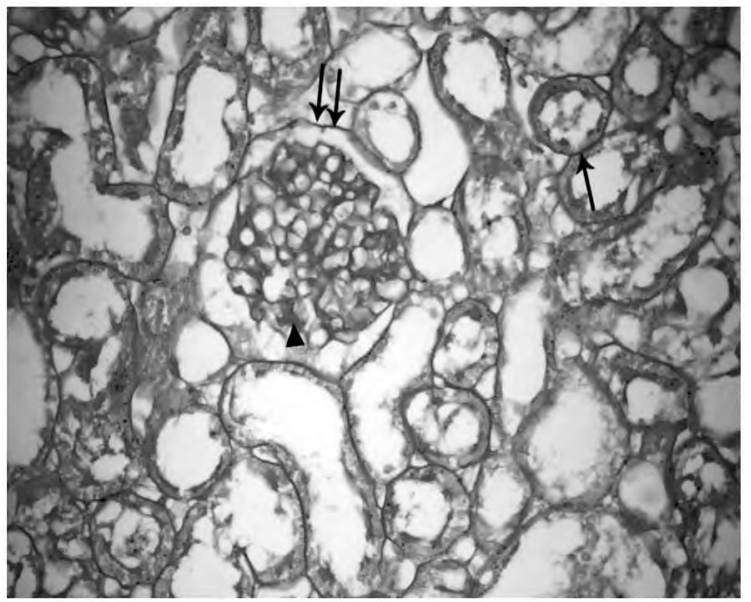

Fig. (9)

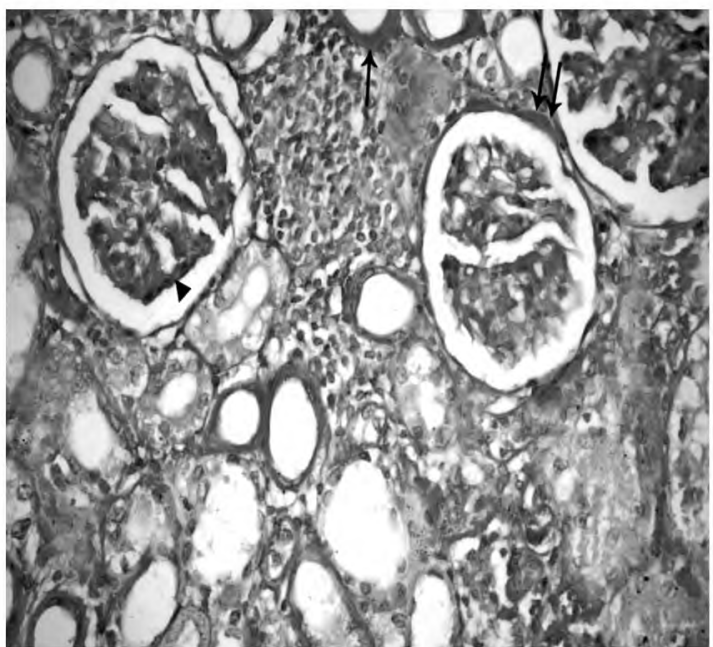

Fig. (11)

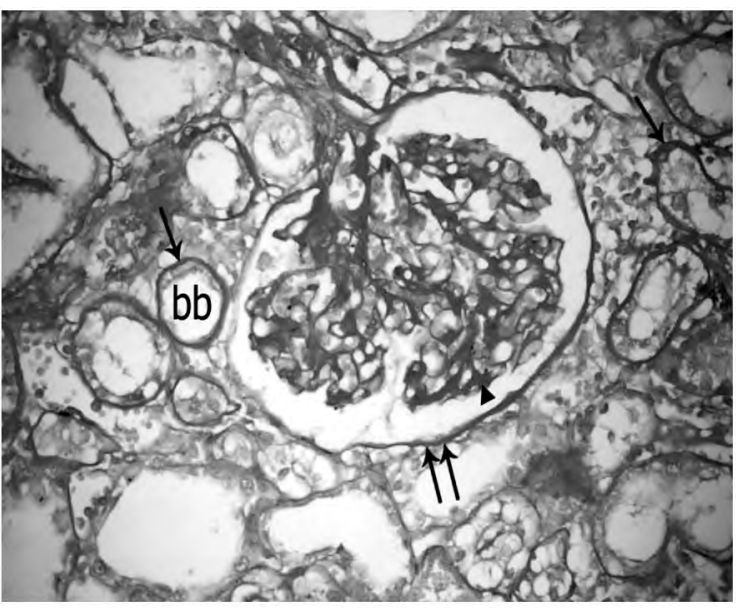

Fig. (8)

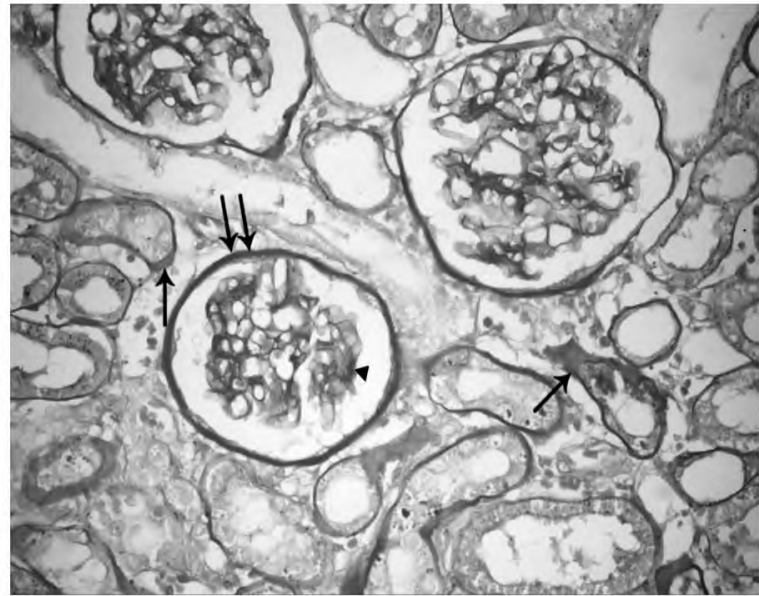

Fig. (10)

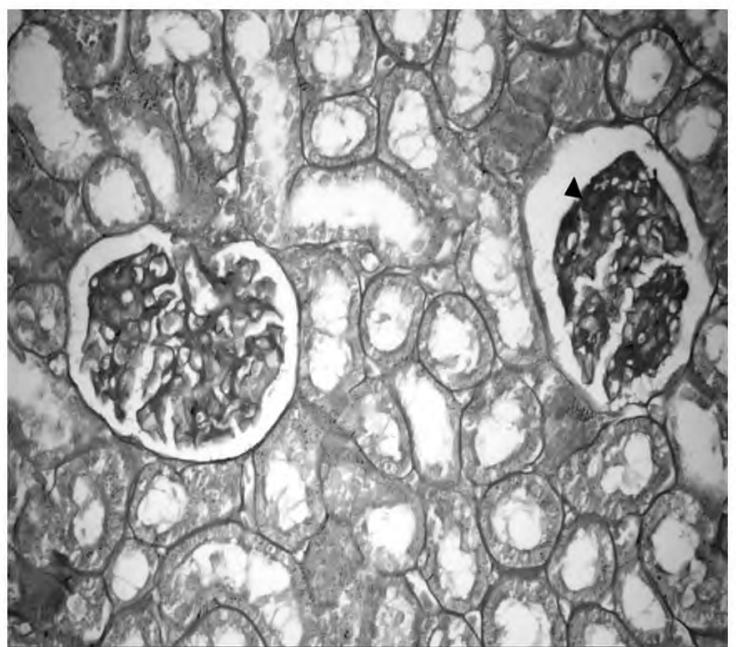

Fig. (12)

Fig. (7): (Control): Showing proximal tubular brush border (arrow head), thin glomerular BM A. Fig. (8): Group II: Showing thickening of the glomerular BM ( ), marked thickening of the tubular BM (arrow) with distorted apical brush border (bb). Fig. (9): Group III: Showing more or less normal glomerular BM ( ) with normal tubular BM (arrow). Fig. 10: Group IV- B: Showing thickening of the glomerular BM ( ) with marked thickening of the tubular BM (arrow). Fig. (11): Group IV- C: Showing thickening of the glomerular BM ( ) with thickening of the tubular BM (arrow). Fig. (12): Group V-B: Showing slight thickening of the glomerular BM ( ). (PASX400). 


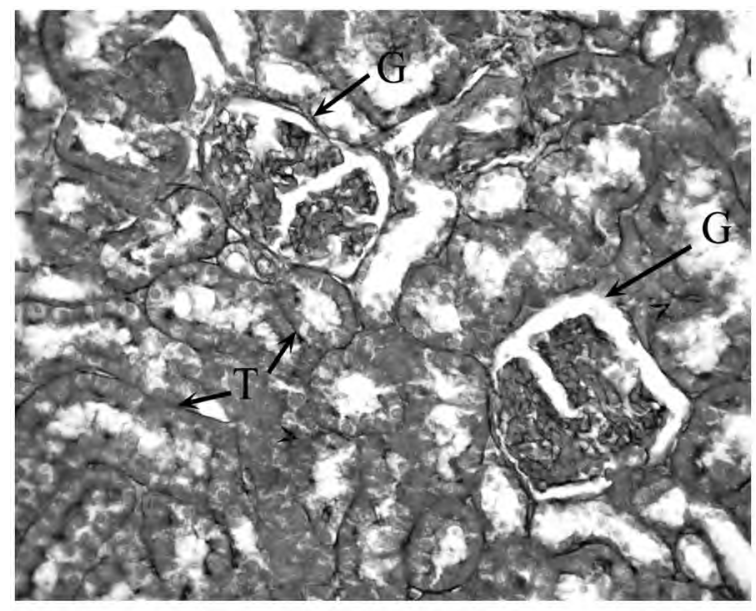

Fig. (13)

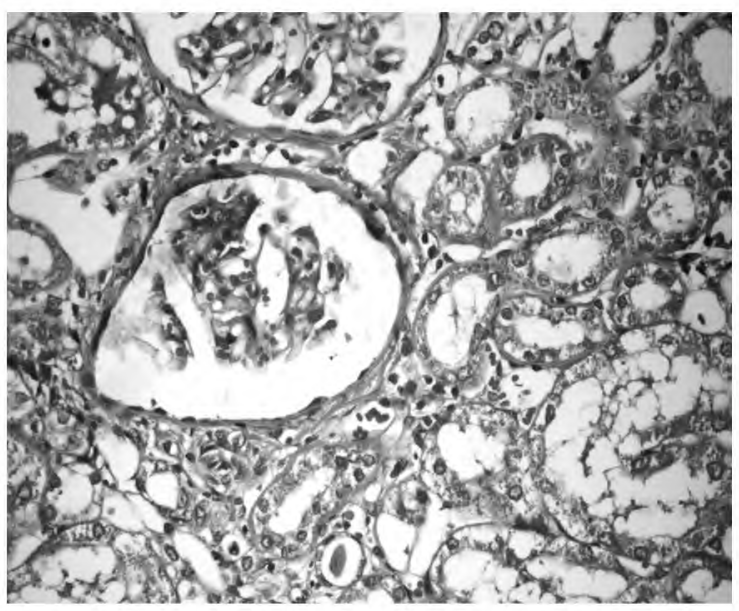

Fig. (15)

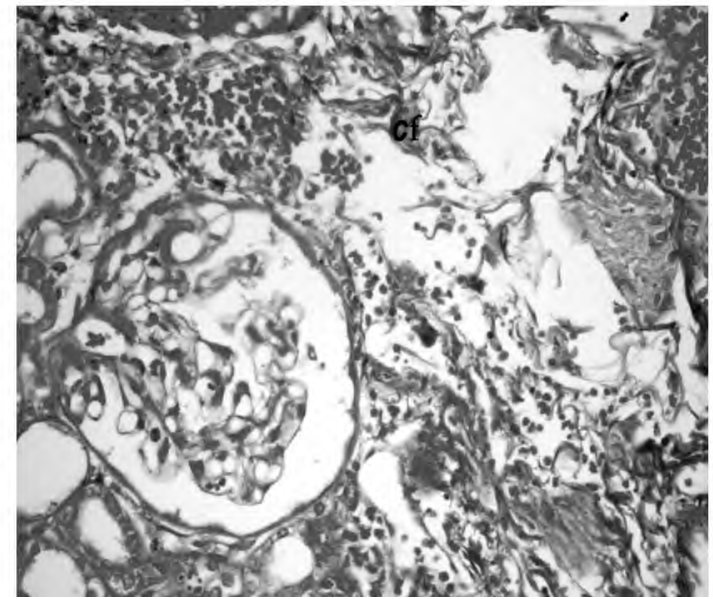

Fig. (17)

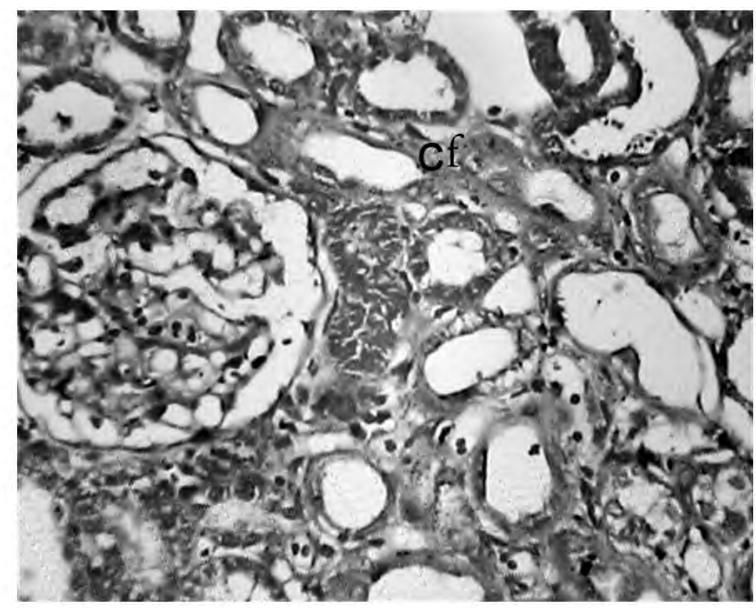

Fig. (14)

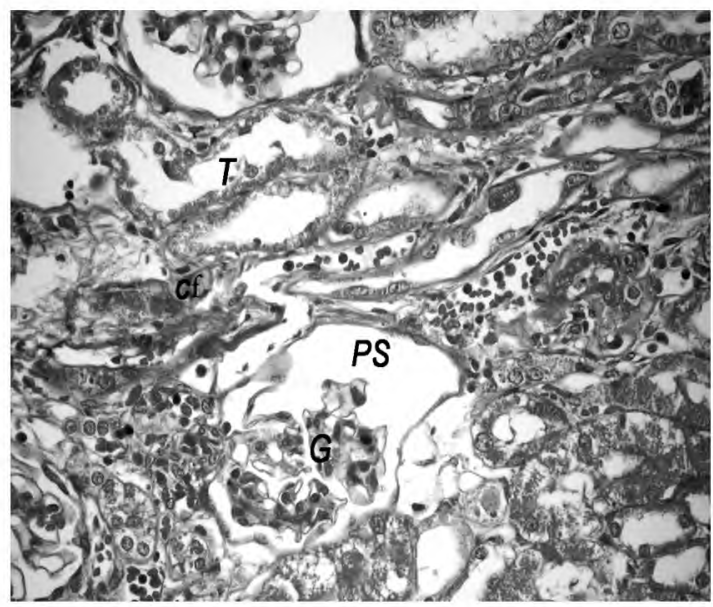

Fig. (16)

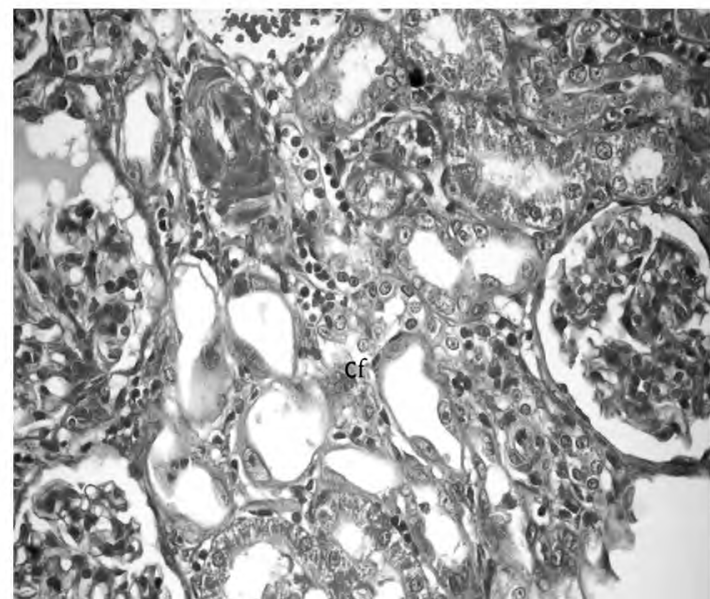

Fig. (18)

Fig. (13): (Control): Showing average distribution of interstitial collagen fibers. Fig. (14): Group II: Showing excess collagen deposition (cf) in the peri-tubular interstitial tissue. Fig. (15): Group III: Showing minimal deposition of collagen fibers in the interstitium of the renal cortex. Fig. (16): Group IV- B: Showing peri-tubular deposition of excess collagen fibers (cf). Fig. (17): Group IV-C: Showing dense deposition of collagen fibers (cf) in the interstitium of the renal cortex. Fig. (18): Group V-B: Showing minimal deposition of collagen fibers (cf) in the renal interstitium. (Masson trichromeX400). 


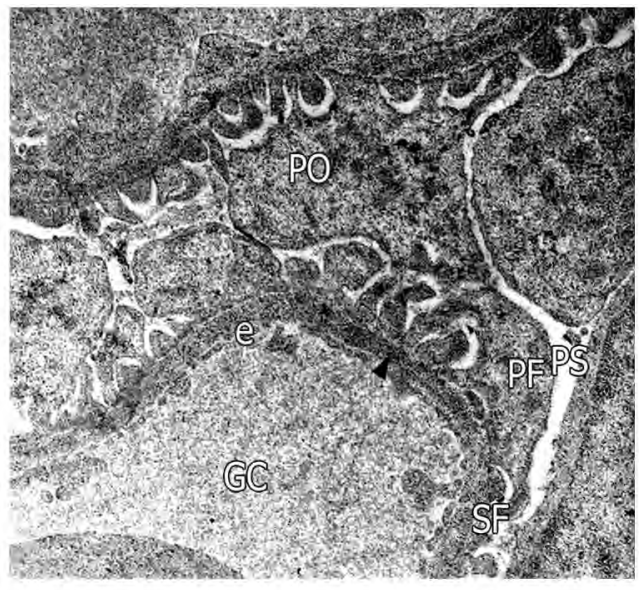

Fig. (19)

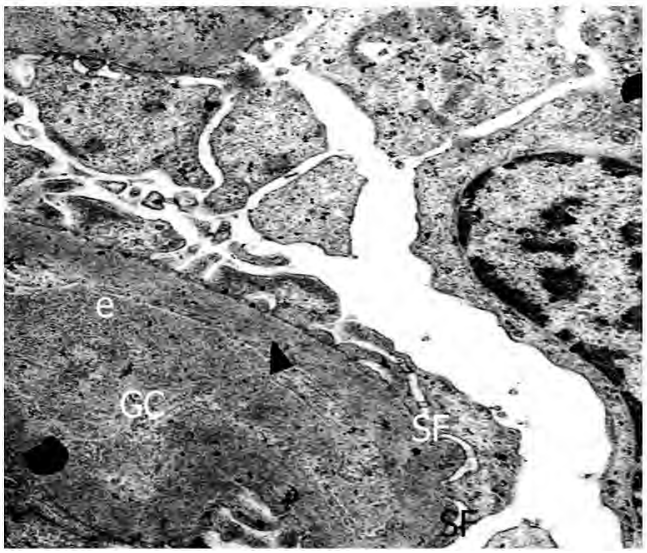

Fig. (21)

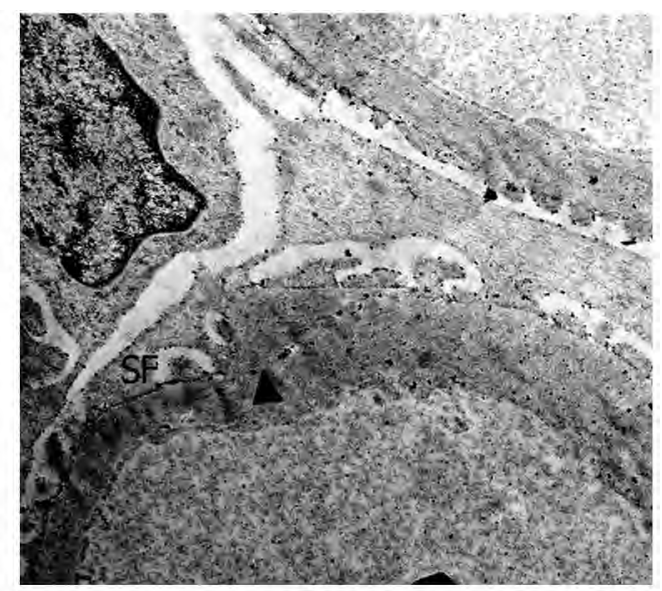

Fig. (20)

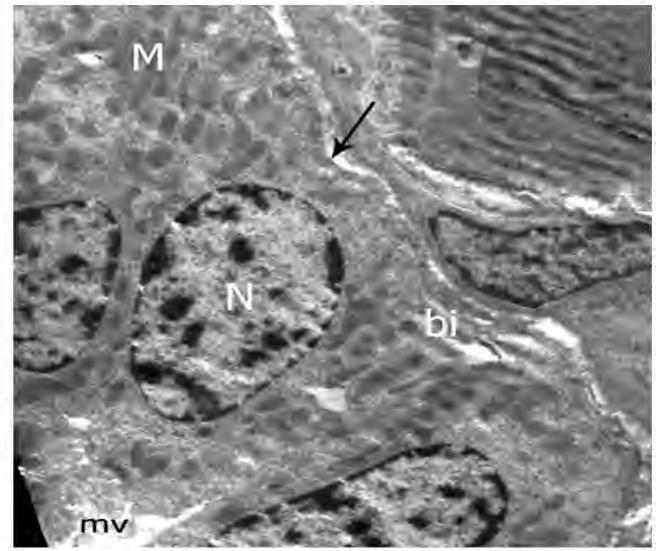

Fig. (22)

Fig. (19): Group I (control): Showing glomerular capillary loops (GC) with average thickness of the tri-laminar glomerular BM ( ), patent fenestrated endothelium (e) lining the glomerular capillaries and primary foot process (PF) of podocyte (PO) giving rise to secondary foot processes (SF), narrow peri-glomerular space (PS) clear of cellular debris. Fig. (20): Group IV-B: showing apparent increase in the thickness of the glomerular BM ( ) and effacement of podocytic secondary foot processes (SF). Fig. (21): Group V-B: Showing glomerular capillary loop (GC) lined by fenestrated endothelium (e), slightly thickened glomerular BM ( ) with normal secondary foot processes (SF) of podocytes. Fig. (22): Group V-B: showing rounded and intact nuclei (N), few and small microvilli (mv), thin BM (arrow) surrounding the distal convoluted tubules and multiple basal elongated mitochondria (M) (EMX20000).

\section{Discussion}

The current study showed that; cisplatin administration caused degenerative changes in the glomeruli, renal tubules and interstitium. This is in agreement with Kuhad et al., [13] and Jisha et al., [14] who reported that nephrotoxicity was the major toxic effect of this compound which sometimes required discontinuation of the treatment. Some studies suggested a role of p53 in tubular cell apoptosis via activation of caspases 6 and 7 genes $[15,16]$

In the present study, kidney sections of rat injected with a single dose of cisplatin (4 weeks) revealed congested shrunken glomeruli, dilated peri-glomerular spaces and thickening of the basement membrane of Bowman' s capsule. Similar findings were reported by Sayed-Ahmed et al., [17], Sevegin et al., [18] who explained that the reduction in the glomerular size was a sequel of glomerular sclerosing process and was an indication of glomerular collapse.

In this study, we choose injection of vitamin C 6 hours before cisplatin administration as Rao et al., [19] who reported that the renal damage induced by cisplatin occurs within one hour after its administration. So, it was necessary that the protective agent must be present in the renal tissues before that time to empower the cell to overcome the toxic effects.

In the present study, administration of vitamin $\mathrm{C}$ before cisplatin revealed marked improvement in the histological picture. These results were in 
agreement with Tarladacalisir et al., [20], who denoted that a significant decrease in the severity of histological changes induced by cisplatin in rat kidney treated with vitamin C plus cisplatin when compared with the cisplatin group. The latter authors concluded that it is possible that the toxic effect of cisplatin is somehow minimized by a compensatory mechanism involving vitamin $\mathrm{C}$ via the induction of antioxidant enzyme activity following injection of cisplatin.

In the current study, the EM examination of the rat kidney specimens of group IV-B demonstrated areas of thickening of the glomerular basement membrane with loss of its tri-laminar appearance and areas of effacement of the secondary foot processes of the podocytes. These data are in close correlation with those reported by Abdelmaguid et al., [21] .

In the current study, the EM showed tubular changes such as shortening and loss of basal infolding, focal loss of brush border, thickening of the tubular BM, many large lysosomes, rounded mitochondria with disordered cristae, small dark nuclei with clumped chromatin and invagination of the nuclear envelope. These results were in agreement with numerous studies in which experimental animals were treated with nephrotoxic heavy metals [21]. Had described shortening and focal loss of microvilli in the proximal tubule cells, a phenomenon that may partially explain a wellknown impairment of reabsorptive and secretory functions of the proximal tubular cells. This may increase the permeability of the membrane and cause the loss of microvilli. An interaction of heavy metals with the proximal tubule cell baso-lateral membrane may lead to fragmentation and loss of baso-lateral invaginations.

We concluded that: Vitamin $\mathrm{C}$ rendered significant protection against cisplatin-induced nephrotoxicity. This protective effect may be partially mediated by preventing the cisplatin-induced decline of renal antioxidant status. The protective effect can also be due to direct scavenging of the free radicals by vitamin $\mathrm{C}$.

\section{References}

1- THADHANI R., PASCUAL M. and BONVENTRE J.V.: Acute renal failure. N. Engl. J. Med., 334: 1448-1460, 1996.

2- WINDSOR R.E., STRAUSS S.J., KALLIS C., WOOD N.E. and WHELAN J.S.: Germline genetic polymorphisms may influence chemotherapy response and disease outcome in osteosarcoma: A pilot study. Cancer, 118 (7): 1856$1867,2012$.
3- KRONING R., LICHTENSTEIN A.K. and NAGAMI G.T.: Sulfur-containing amino acids decrease cisplatin cytotoxicity and uptake in renal tubule epithelial cell lines. Cancer Chemother Pharmacol., 45: 43-49, 2000.

4- LIEBERTHAL W, TRIACA V and LEVINE J.: Mechanisms of death induced by cisplatin in proximal tubular epithelial cells: Apoptosis versus necrosis. Am. J. Physiol., 270: 700-708, 1996.

5- KAWAI Y., NAKAO T., KUNIMURA N., et al.: Relationship of intracellular calcium and oxygen radicals to Cisplatin-related renal cell injury. J. Pharmacol. Sci., 100: 65-72, 2006.

6- LEONETTI C., BIROCCIO A., GABELLINI C., SCARSELLA M., MARESCA V., FLORI E., BOVE L., PACE A., et al.: Alpha-tocopherol protects against cisplatininduced toxicity without interfering with antitumor efficacy. International Journal of Cancer, 104: 243-250, 2003.

7- MCGREGOR G.P. and BIESALSKI H.K.: Rationale and impact of vitamin $\mathrm{C}$ in clinical nutrition. Current Opinion in Clinical Nutrition and Metabolic Care, 9 (6): 697-703, 2006.

8- KARIMI G., RAMEZANI M. and TAHOONIAN Z.: Cisplatin nephrotoxicity and protection by milk thistle extract in rats. Evid Based Complement. Alternat. Med., 2: 383-386, 2005 .

9- PADAYATTY S.J., KATZ A., WANG Y., et al.: Vitamin $\mathrm{C}$ as an antioxidant: Evaluation of its role in disease prevention. Journal of the American College of Nutrition, 22 (1): 18-35, 2003.

10- TARLADACALISIR Y.T., KANTER M. and UYGUN M.: Protective effects of vitamin $C$ on cisplatin-induced renal damage: A light and electron microscopic study. Ren. Fail., 30 (1): 1-8, 2008.

11- FATIMA S. and MAHMOUD R.: Vitamin C attenuates potassium dichromate-induced nephrotoxicity and alterations in renal brush border membrane enzymes and phosphate transport in rats. Clin. Chim. Acta., $386(1-2)$ : 94-99, 2007.

12- YAMATE J., ISHIDA A., TSUJINO K., TATSUMI M., NAKATSUJI S., KUWAMURA M., KOTANI T. and SAKUMA S.: Immunohistochemical study of rat renal interstitial fibrosis induced by repeated injection of cisplatin, with special reference to the kinetics of macrophages and myofibroblasts. Toxicol. Pathol., 24: 199206, 1996.

13- KUHAD A., TIRKEY N., PILKHWAL S. and CHOPRA K.: Renoprotective effect of spirulina fusiformis on cisplatin-induced oxidative stress and renal dysfunction in rat. Ren. Fail., 28 (3): 247-254, 2006.

14- JISHA J. and CHERUPALLY N.: Amelioration of cisplatin nephrotoxicity in Swiss albino mice by Rubia corifolia extract. J. of Cancer. Res. and Ther., 4 (3): 111-115, 2008.

15-YANG C., KAUSHAL V., HAUN R.S., SETH R., SHAH S.V. and KAUSHAL G.P.: Transcriptional activation of caspase- 6 and -7 genes by cisplatin-induced p53 and its functional significance in cisplatin nephrotoxicity. Cell. Death. Differ., 15: 530-544, 2008.

16- CHIRINO Y.I. and PEDRAZA-CHAVERRI J.: Role of oxidative and nitrosative stress in cisplatin-induced nephrotoxicity. Exp. Toxicol. Pathol., 61: 223-242, 2009. 
17- SAYED-AHMED M.S., EISSA M.A., KENAWAY S.A., MOSTAFA N., CALVANI M. and OSMAN AM.: Progression of cisplatin-induced nephrotoxicity in a carnitine depleted rat model. Chemother., 50: 162-170, 2004.

18- SEVGIN I., FERIHA E., NURSAL G., MERAL G. and INCI A.: Simvastatin attenuates cisplatin-induced kidney and liver damage in rats. Toxicol., 230: 256-264, 2007.

19- RAO M. and RAO M.M.: Protective effects of selenom- ethionine against cisplatin-induced renal toxicity in mice and rats. J. Pharm. Pharmacol., 50: 687-691, 1992.

20- TARLADACALISIR Y.T., KANTER M. and UYGUN M.: Protective effects of vitamin $C$ on cisplatin-induced renal damage: A light and electron microscopic study. Ren. Fail., 30 (1): 1-8, 2008.

21- ABDELMEGUID N.E., CHMAISSE H.N. and ABOU ZEINAB N.S.: Protective Effect of Silymarin on Cisplatininduced Nephrotoxicity in Rats. Pak. J. Nutr., 9 (7): 624636, 2010.

\title{
تأثير عقار السيسبلاتين على الكلى فى الجرذان البيضاء

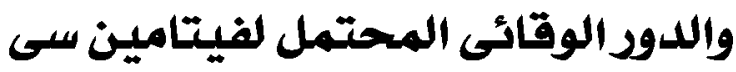

\author{
أجريت هذه الدراسة على •آمن الجردان البيضاء البالغة وتم تقسيمهم إلى خمس مجموعات:

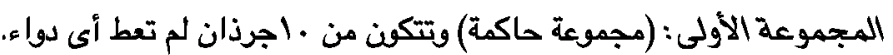 \\ المجموعة الثانية: تتكون من · اجرذان تم إعطاؤها جرعة واحدة من السيسبلاتين داخل (الصفاق المجم/كجم).
}

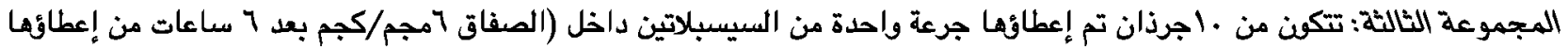

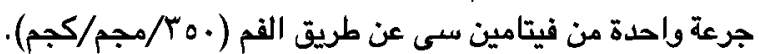

وقد أحذت عينات الكلى من حيوانات المجموعتين الثانية والثالثة بعد ع أسابيع من بداية التجربة.

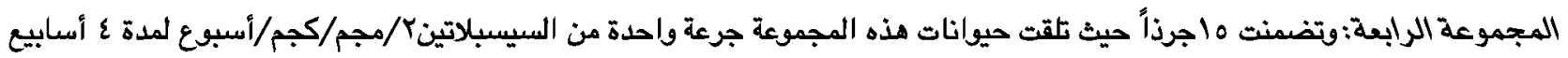

$$
\text { داخل الصفاق. }
$$

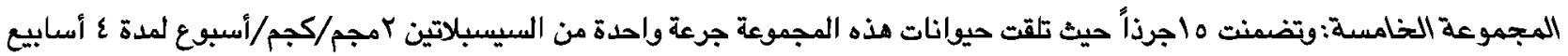

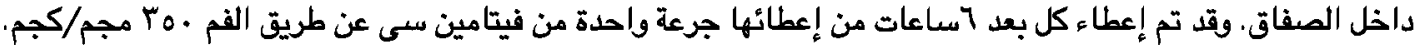

$$
\text { المجموعات الفرعية: المبر }
$$

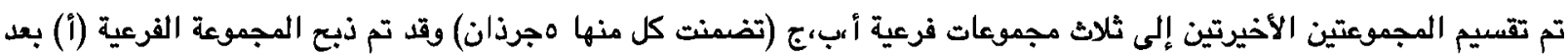

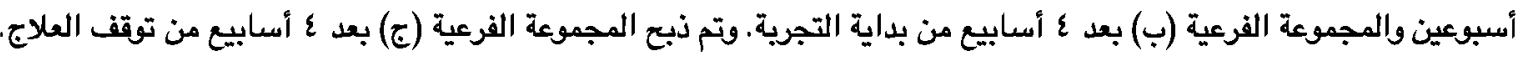

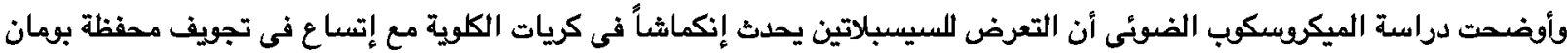

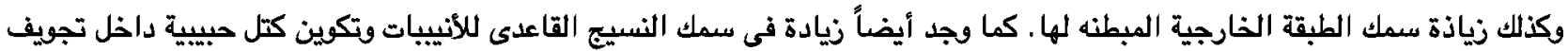

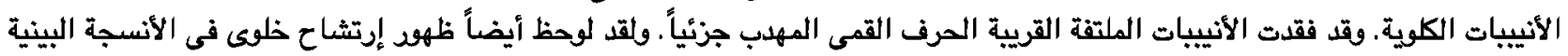
الكلوية مع وجود إحتقان دموى وكذلك زيادة فى نسبة ألياف الأنسجة البينية.

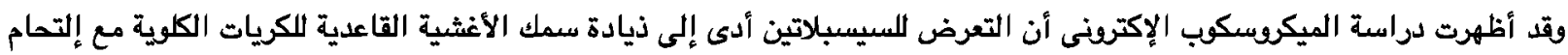

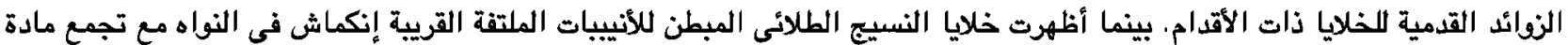
الكروماتين. وقد وجد زيارة في عدد الليزونومات وتقلص في الميتوكوندريا مع فقدان الأعراف وفقدان الإنطواءعات القاعدية.

وقد خلصت نتائج هذه الدراسة إلى أن فيتامين سى أحدث وقاية ملحوظة ضد الضرد الكلوى التاكسدى الناجم عن السيسبلاتين. هذا

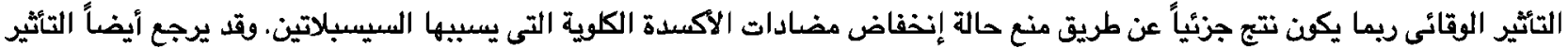

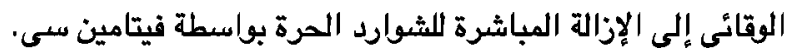

